\title{
A POESIA DE JOÃo AIRAS DE SANTIAGO E A LITERATURA BÍBLICA SAPIENCIAL*
}

Rafaela Silva

https://orcid.org/0000-0002-1200-3482

Carla Correia***

https://orcid.org/0000-0002-8182-2916

Como citar este artigo: SILVA, R.; CORREIA, C. A poesia de João Airas de Santiago e a literatura bíblica sapiencial. Todas as Letras - Revista de Língua e Literatura, São Paulo, v. 23, n. 3, p. 1-12, set./dez. 2021. DOI 10.5935/1980-6914/eLETDO 2114813

Submissão: setembro de 2021. Aceite: novembro de 2021.

Resumo: O universo poético de João Airas de Santiago não se encerra apenas nas 81 composições que chegaram até nós. Partindo de um cantar de amor que apresenta características próprias do sirventês moral, veremos como o burguês de Santiago reflete sobre vários aspetos do comportamento humano, bebendo das suas leituras do livro Eclesiastes. Com a análise desta notável intertextualidade, pretendemos mostrar como a presença do pensamento bíblico nos textos do trovador parece servir à legitimação da atividade trovadoresca, possibilitada pelo amor.

Palavras-chave: Bíblia. Eclesiastes. João Airas. Lírica trovadoresca. Literatura medieval.

\footnotetext{
* Este artigo foi desenvolvido no âmbito do projeto "Da Memória Escrita à Leitura do Espaço" (Mele) (POCI-01-0145-FEDER032673), cofinanciado pelo Programa Operacional Competitividade e Internacionalização (Poci), através do Portugal 2020 e do Fundo Europeu de Desenvolvimento Regional (Feder), e por fundos nacionais através da Fundação para a Ciência e a Tecnologia (FTC).

** Universidade do Porto, Porto, Portugal. E-mail: rafaelasilva84@hotmail.com

*** Universidade do Porto, Porto, Portugal. E-mail: carlasofia.04@gmail.com
} 
importância que o corpus poético do trovador João Airas de Santiago tem no seio dos cancioneiros medievais galego-portugueses é já largamente reconhecida, não apenas pela sua fecundidade, mas, sobretudo, pela sua originalidade. Compondo nos três principais géneros - amigo, amor e escárnio e maldizer -, é, principalmente, dentro dos dois primeiros que é mais profícuo. Inserindo-se ideologicamente numa corrente d'amigo, que dialoga com o género de amor, subvertendo-o, João Airas imprime nas suas composições, em vários momentos, elementos insólitos ${ }^{1}$ e estranhos àquilo que seria habitual na poesia galego-portuguesa, colocando-a em permanente diálogo consigo mesma e deixando adivinhar um conhecimento profundo dos modelos occitânicos que lhe deram origem ${ }^{2}$.

Sabemos hoje que os textos dos autores que fizeram parte das duas primeiras gerações de trovadores galego-portugueses manifestavam uma ideologia de grupo, a da nobreza senhorial, com reivindicações muito próprias ${ }^{3}$. Essa ideologia foi determinante para a evolução do género de amor, tendo culminado na criação de uma nova linguagem poética veiculada pelo género de amigo. Por seu lado, os cantares do trovador galego, não parecendo fazer ressonância dessa funcionalidade social, aparentam antes explorar esse universo poético, marcadamente disfórico, pintando-o de outros tons mais otimistas, reinventando-o e colocando-o em permanente diálogo com os modelos transpirenaicos. Esta complexa operação de renovação poética imprime à sua poesia uma singularidade muito própria, que deixou eco nos trovadores que se seguiram.

Conhecido este carácter inovador da poesia do burguês de Santiago, atrevemo-nos a explorar outro universo literário, o bíblico, que, estando já reconhecidamente na génese de várias composições trovadorescas ${ }^{4}$, nos parece influenciar de forma notória o texto do nosso trovador que abaixo transcrevemos.

Algun ben mi deve ced' a fazer

Deus, e fara mi-o quando Lh' aprouguer; sempr' ando led' e quen mi falar quer

en pesar, non tho posso padecer,

mais fuj' ant' el e non lho quer' oir;

des $i$ ar ei gran sabor de guarir

con quen sei que quer falar en prazer.

Ca todos andan cuidando aver

e outra ren non queren cuidar ja,

e morren ced' e fica tod' aca;

mais esto migo non poden põer,

que trob' e cant' e cuido sempr' en ben,

1 Por exemplo, em B1028/ V618 desenvolve o tema da guarda, mas a guardar a amiga parece estar uma personagem masculina, e não uma feminina, como era habitual; e em V595 e V599, a mãe incentiva a relação dos namorados, atuando como coadjuvante da relação amorosa, contrariamente ao que era comum.

2 Plasmado na preferência pelo tom mais otimista da generalidade das suas composições, bem como na utilização de outros géneros literários mais comuns à poesia transpirenaica, como a pastorela.

3 Sobre o tema, ver Miranda e Oliveira (1995).

4 Carolina Michaëlis de Vasconcellos (1990, p. 624) considera que a imagem do cervo das cantigas de Pero Meogo provém do conhecimento do Salmo 42. Para Aubrey Bell (1922), essa imagem deriva do Cântico dos Cânticos. Alan Deyermond (1992) estabeleceu o Salmo 86 como fonte da única composição de Meendinho que chegou até nós. No seguimento desse autor, Maria do Rosário Ferreira e José Carlos Ribeiro Miranda (2003) aprofundaram essa questão. Segundo Miranda (2004, p. 118-119), também Osoir'Anes Marinho se terá inspirado no Cântico dos Cânticos ao compor o cantar E por que me desamade. Já Ferreira (1999, p. 143) explora as imagens do Cântico dos Cânticos em Levad'amigo que dormid'las mananas frias, de Nuno Fernandes Torneol. 
e tenh' amiga que faz mui bon sén,

e pod' o tempo passar en prazer.

Nostro Senhor, que á mui gran poder,

é sempre ledo no seu coraçon,

e son mui ledos quantos con $\mathrm{El}$ son;

por én faz mal, quant' é meu conhocer,

o que trist' é, que sempre cuida mal,

ca un pobre ledo mil tanto val

ca rico triste en que non á prazer (BASE DE DATOS, B963/V549).

Estamos perante um cantar que, pese embora cumprir o critério para ser classificado no género de amor, apresenta uma temática moral que o torna de dificil categorização. Nele, o sujeito poético começa por referir que é provável que seja em breve agraciado com um ben de Deus, pois anda alegre e trata de se afastar de quem só lhe fala em sofrimento - pesar. Esta referência ao bem pode ser transportada, no contexto da linguagem trovadoresca, para a recompensa que, no caso da relação estabelecida com a dona, é sempre amorosa. Ainda neste contexto, Deus é frequentemente invocado como aquele que pode ou não proporcionar esse bem ${ }^{5}$, através da ação da mulher. Contudo, não parece ser esse o sentido que o termo adquire no texto de João Airas. Neste caso, o bem parece emanar diretamente de Deus, e não da dona por intermédio da ação divina, aparecendo intimamente ligado à sensação de bem-estar experimentada pelo nosso trovador - o prazer, repetido no final de todas as estrofes -, e contrastando com a tristeza - pesar - daqueles que a ele se dirigem. Mas qual a origem da alegria que caracteriza o comportamento do trovador e a da tristeza dos que o abordam? O pesar estaria relacionado com as preocupações e inquietações dos que amontoam riquezas - "andam cuidando em aver" -, já o prazer com a atividade do sujeito poético que "trob'e cant". Assim, podemos considerar que, para o trovador, o ben será experimentado em resultado do trovar e do cantar, da mesma maneira que o pesar, em consequência da acumulação de riqueza.

Ora, esta exposição de João Airas leva-nos ao Eclesiastes (Qohelet ${ }^{6}$ ), o livro de género sapiencial do Antigo Testamento, classificado no cânone hebraico entre os ketuvim (escritos), paladino da reflexão acerca da vida humana e do seu sentido $^{7}$. Este livro bíblico sintetiza as observações e experiência do seu autor, identificado no prólogo como "filho de David, rei em Jerusalém" (Eclesiastes 1:1) Salomão, o rei sábio. A estrutura do Qohelet, reforçada na repetida menção do termo hebel, palavra hebraica que significa "sopro", "vapor" comummente traduzida na Bíblia por "vaidade" ou "vanidade" 9 , corrobora a mensagem central deste livro, com repercussão universal e cariz escatológico ${ }^{10}$ : toda a iniciativa humana será inútil, vã, a menos que seja legitimada pelo divino Juiz, cujas obras são repletas de sentido.

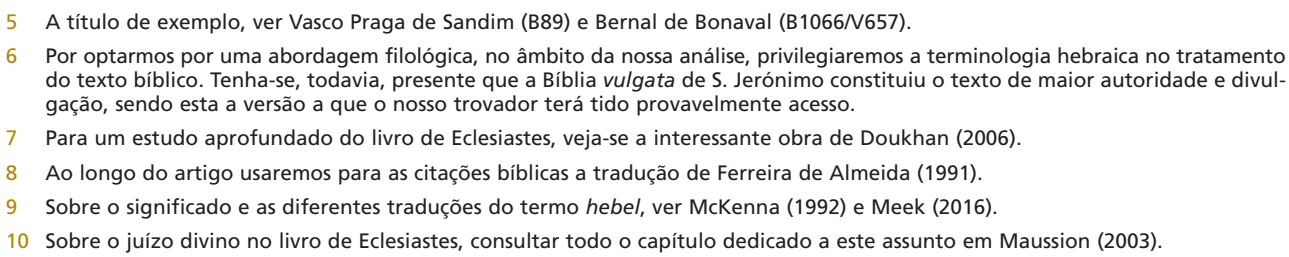


Mas em que medida o texto de João Airas se aproxima do livro bíblico enunciado e com que propósito teria este trovador buscado no Qolehet a sua inspiração, tendo em conta o caráter acentuadamente teológico deste livro da Bíblia, tão contrastante com a natureza profana do amor cortês, habitualmente representada e cantada neste género de composições?

Em primeiro lugar, a temática da alegria, presente no texto através da evocação do ben e do prazer (e, indiretamente, o seu oposto - a tristeza), tem também um lugar preponderante nas sentenças do Qohelet, sempre perspetivada na consideração daquilo que é proveitoso (yithron) ou vão (hebel) entre as virtudes e iniciativas humanas (cf. Eclesiastes $1: 3 ; 2: 11 ; 3: 9 ; 5: 9 ; 16)$. Com efeito, a experiência e escrutínio do Qohelet levam-no a concluir que a verdadeira e duradoura alegria só poderá ser desfrutada por aqueles que cumprem cada dever, cada tarefa, por mais trivial que também possa ser, com a consciência de que todos serão avaliados por Deus (cf. Eclesiastes 3:17; 12:14). Este pensamento e os motivos que em torno deste assunto são desenvolvidos no livro de Eclesiastes são, segundo cremos, transportados e urdidos pelo trovador num contexto um pouco diverso do bíblico, mas perfeitamente ajustável à realidade agora cantada.

É, porém, necessário notar que, de acordo com o pensamento bíblico, e admitindo a possibilidade de o nosso trovador "beber" dessa influência para (re)dimensionar estas duas noções na sua composição, o bem que o sujeito poético diz receber de Deus e o prazer que dele resulta apenas se conjugam e são válidos na medida em que se harmonizam com a ideia defendida ao longo do Qohelet: o bem e o prazer ${ }^{11}$ advêm de uma escolha legitimada por Deus, ou seja, priorizada na consciência de que qualquer obra humana é presenciada e avaliada pelo divino Juiz. A menção que é feita à figura divina logo no início deste cantar parece indiciar esse mesmo discernimento, sendo bastante significativa, pois nela se estabelece a autoridade máxima ("Deus...quando Lh'aprouguer") quanto ao assunto apresentado. Além disso, este ben referido poderá eventualmente situar-se, sob o mesmo ponto de vista bíblico, na esfera do perdurável, que se opõe ao efémero e vão (hebel), redundando, por isso, em prazer (alegria), numa satisfação plena decorrente da aprovação divina. Repare-se que, embora a palavra "vanidade" (hebel), tão reiterada e estruturante em Eclesiastes ${ }^{12}$, não esteja patente na composição de João Airas, poderá estar subentendida na segunda estrofe, ao apontar o trovador que todos se preocupam demasiado com a fortuna - aver, mas que, morrendo, nada levam consigo - "morren ced' e fica tod' aca". Esta constatação do sujeito poético relembra, uma vez mais, as diversas considerações do Qohelet concernentes ao insaciável desejo dos homens na aquisição dos bens materiais, quando observa que "O que ama o dinheiro não se fartará dele; quem ama a abundância nunca se farta da renda" (Eclesiastes 5:10) e que "a fartura do rico não o deixa dormir" (Eclesiastes 5:12), pois será inútil amontoar riquezas, uma vez que "Como saiu do ventre da sua mãe, assim nu voltará, indo-se como veio; nada tomará do seu trabalho, que possa levar na sua mão... que proveito lhe vem de trabalhar para o vento?" (Eclesiastes 5:15-16) ${ }^{13}$.

\footnotetext{
11 No livro de Eclesiastes a palavra que mais corresponderá ao que aqui designamos "prazer" será em hebraico simchah ou samach, traduzida por "alegria" (Eclesiastes 1:10; 2:26; 3:12, 22; 5:19-20).

12 Veja-se Weeks (2020, p. 20-29).

13 A mesma reflexão é explanada no livro de Provérbios, compilação atribuída igualmente ao mesmo filho de David, o rei Salomão (Provérbios 1:1): "Não te canses para enriqueceres... Fitarás os olhos naquilo que não é nada?" (Provérbios 23:4-5); "[...] as riquezas não duram para sempre" (Provérbios 27:24); "A riqueza nada vale no dia da ira" (Provérbios 11:4).
} 
Desta possivel intertextualidade bíblica sobressai ainda uma estreita ligação estabelecida entre o ben (o trovar e o cantar) e o trabalho. É interessante notar que a observação realizada no seio do Qohelet a este propósito é quase sempre delimitada entre dois polos, anteriormente evocados: por um lado, o vão, que é sopro (hebel), inevitavelmente passageiro e rapidamente inexistente, e por outro lado, o duradouro, o que é eterno (olam) (cf. Eclesiastes 1:4; 2:16; 3:11, 14; 12:5). A indagação atinente às obras humanas, encabeçada pelo filho de David, passa igualmente por esta categorização. O trabalho empreendido pelos homens e os seus frutos são, assim, minuciosamente examinados pelo rei de Jerusalém, começando essa investigação pela avaliação da sua própria experiência. A uma conclusão vai ele chegando no final de cada observação, repetidamente comunicada:

Não há nada melhor para o homem do que comer, beber e fazer que a sua alma goze do bem do seu trabalho. Vi que isto também vem da mão de Deus (Eclesiastes 2:24, grifo nosso).

Sei que não há coisa melhor para eles do que se alegrarem e fazerem o bem na sua vida; e também que todo homem coma e beba, e goze do bem de todo o seu trabalho; é isto dom de Deus (Eclesiastes 3:12-13, grifo nosso).

Então percebi uma boa e bela coisa: alguém comer e beber, e gozar cada um do bem de todo o seu trabalho, com que se afadigou debaixo do sol, todos os dias da vida que Deus the deu; esta é a sua porção. Quanto ao homem a quem Deus deu riquezas e bens, e lhe deu poder para delas comer, e tomar a sua porção, e gozar do seu trabalho: isto é dom de Deus (Eclesiastes 5:18, grifo nosso).

Também o fruto do trabalho, ou por outras palavras, o proveito por essa via conquistado, assenta, tal como anteriormente referimos quanto à questão do bem e do prazer, na consciência de que consiste numa dádiva divina, tão vincada ao longo de Eclesiastes. É, neste prisma, muito significativo o que no final de cada conclusão é dito, "isso vem da mão de Deus" ou "é dom de Deus". Este autêntico refrão permite classificar o bem adquirido através do trabalho e o regozijo que dele resulta entre aquilo que não é "vão" (hebel), mas perene ou de repercussões eternas relacionadas com o Juizo divino (cf. Eclesiastes 3:17). Neste quadro, o filho de David precisa que "ao homem que é bom diante dele, Deus dá sabedoria, e conhecimento e alegria" (Eclesiastes 2:26), ou seja, o que assim procede benignamente ${ }^{14}$, trabalhando, vive verdadeiramente feliz. Ora, é uma condição muito semelhante a esta, descrita no Qohelet, que o nosso trovador parece experimentar. Apesar de o termo "trabalho" não constar na composição poética, tem no trovar e cantar (trob' e cant') o seu equivalente. A ser assim, e plasmando-se também nesta questão o raciocínio do nosso trovador no Qohelet, o ben aguardado pelo sujeito poético e recebido da parte de Deus poderá ser entendido como o proveito (o prazer) que deriva da sua atividade trovadoresca, o que explicaria, ainda, a alegria que diz desfrutar e com que deseja sempre conviver, como deixa transparecer ao longo de todo o texto.

Nesta ligação de matriz bíblica assinalada entre o bem e o trabalho devemos, todavia, ter em conta uma diferenciação existente entre duas conceções de trabalho. Se é verdade que o termo surge inúmeras vezes registado no Qohelet,

14 A palavra towb, significando o que é "bom", "benigno" (RAYMOND, 1991), aparece, de facto, insistentemente ao longo do Qohelet. 
abordado como um dos principais assuntos e objeto de observação por parte do sábio filho de David, dois conceitos diferentes são aí geralmente traduzidos por "trabalho", constituindo, porém, palavras muito distintas no texto hebraico. Com efeito, este livro veterotestamentário abarca dois termos - amal (cf. Eclesiastes $1: 3,10 ; 2: 21,24 ; 3: 9,13 ; 5: 18-19$ ) e inyan (cf. Eclesiastes $1: 13 ; 2: 23,26 ; 3: 10$; $4: 8)$. No âmbito do Qohelet, o primeiro reporta-se ao trabalho propriamente dito, ao labor, e o segundo, à ocupação, à tarefa, ao esforço desmedido e penoso ${ }^{15}$. Curioso será notar que apenas amal deixa de ser "vão" (hebel), sendo empregado com uma conotação positiva neste livro das Escrituras, unicamente quando o "trabalho" é legitimado e recompensado por Deus, servindo para um propósito específico. Quanto à ocupação penosa envolvida na palavra inyan, esta é irremediavelmente considerada "vã" ao longo de todo o texto, associada, por exemplo, à acumulação de riquezas que nunca satisfazem, ou que causam dano à saúde pelo excessivo tempo gasto para as adquirir (Eclesiastes 5:10-17), trazendo na realidade inquietação e tristeza. De facto, outro refrão, completamente oposto àquele que acima sublinhámos, acompanha o sentido envolvido na palavra inyan - "isto também é vaidade e desejo vão" (Eclesiastes 2:26) ${ }^{16}$.

Perante esta explanação, facilmente percebemos em qual destas conceções bíblicas de trabalho se enquadra a atividade do nosso trovador. Para João Airas, a alegria e o prazer provêm da prática do cantar e trovar, possibilitada e motivada pela existência de uma mulher (a amiga) e, principalmente, porque esse trabalho é legitimado pelo próprio Deus, como se depreende pela alusão inicial à figura divina, que confere autoridade e valor ao ben anunciado. O trovar, que à mulher está associado, torna-se, por conseguinte, sinónimo de alegria e prazer, mas sobretudo, e à luz da convocação de sentido bíblico, tudo isto constitui uma bênção divina. Ou seja, o trovador, mesmo não utilizando o termo, aproxima-se da primeira conceção de trabalho descrita no Qohelet (amal), aquela em que a sua atividade lhe vai permitir usufruir de tudo o que de positivo dela advém. Por outro lado, a segunda noção de trabalho (inyan) não está ausente do texto, parecendo estar implícita na referência que o nosso trovador faz aos que "andam cuindando em aver" e que, por isso, vivem em desassossego e tristeza. Assim, para além de se servir da oposição alegria versus tristeza, o nosso trovador aproveita também esta diferenciação positiva e negativa do trabalho como forma de legitimar a atividade trovadoresca.

Se até aqui o pensamento do burguês de Santiago parece estar em perfeita sintonia com as ideias que são transmitidas de forma insistente pelo Qohelet, é no aflorar da figura da amiga que encontramos a principal divergência. Embora o livro bíblico também incentive a gozar "[...] a vida com a mulher que amas [...] porque esta é a tua porção nesta vida" (Eclesiastes 9:9), de forma aparentemente paradoxal, a mulher é encarada como traiçoeira - "Achei uma coisa mais amarga do que a morte, a mulher, cujo coração são redes e laços, e cujas mãos são grilhões" (Eclesiastes 7:26). O problema parece ganhar maiores proporções

\footnotetext{
15 Estas duas conceções diferentes de "trabalho" estão de alguma forma também presentes na Bíblia vulgata. A primeira, correspondente a amal, é traduzida em latim por labore (cf. Eclesiastes 1:3; 2:19; 3:9, 3:13); a segunda (inyan no texto hebraico) manifesta uma maior variabilidade na tradução em latim - occupatio (Eclesiastes 2:23), afflictionem (cf. Eclesiastes 2:26), cura (Eclesiastes 5:3). O texto de Eclesiastes transmitido na General estoria não apresenta a mesma dualidade de sentido comunicada no texto hebraico (AFONSO X, 1930, p. 461-474). A ser assim, e considerando que a General estoria poderia ter constituído uma fonte textual para a composição do nosso trovador, contemporâneo de Afonso X, tendo estado presente na corte do rei Sábio, fica invalidada essa hipótese.

16 Cf. Eclesiastes 2:23; 4:8.
} 
quando o Qohelet declara: "[...] um homem entre mil achei, mas uma mulher entre todas não achei” (Eclesiastes 7:28). Assim, se do lado do Qohelet o filho de David não encontra qualquer mulher digna de menção, do lado do nosso cantar do amor, a mulher é caracterizada como sensata, "que faz mui bom sen". A ser assim, o trovador de Santiago parece retirar do texto bíblico aquilo que estaria em consonância com a mensagem que queria transmitir, adaptando-o ao seu universo e justificando ao mesmo tempo a sua legitimidade no exercício do trobar e cantar motivado pela amiga.

A sensatez - agora não da mulher, mas do amante - é um tema já aflorado por João Airas noutro cantar de amor (BASE DE DATOS, B953/V541), no qual faz um jogo entre as diferentes aceções da palavra ben. O sujeito poético começa por declarar desejar obter o bem - a recompensa amorosa - da sua senhora, mas apenas se isto não lhe trouxer mal a ela, ou seja, se não manchar a sua reputação. Assim, porque o mal dela será um mal para ele, recusa querer um tal bem. $\mathrm{O}$ trovador vai ainda mais longe e aponta o egoísmo de quem o exige sem se preocupar com o que daí advirá para a mulher, sentenciando que esses não amam verdadeiramente, amam-se sim a si próprios ${ }^{17}$.

Ora, estas teorizações sobre aquilo que deve ser o amor confrontam de forma muito evidente toda a poética de amor e amigo galego-portuguesa. O bem já não é algo que se possa exigir se tal atitude prejudicar o bem-estar da mulher, e a posição do sujeito poético, em vez de ser de sofrimento e agonia, é antes de resignação e de contentamento, pois o bem da dona é o seu próprio bem. Assim, o trabalho trovadoresco edifica-se em resultado da ação de uma figura feminina que, além de ser sensata, também desperta comportamentos ponderados e cautelosos no amante, aproximando-se aqui da ideia de mesura, como os provençais a concebiam ${ }^{18}$.

Quando o trovador aborda este tema da sensatez, está também, de forma indireta, a abordar o seu oposto. A insensatez dos homens pode manifestar-se, como vimos, na forma como abordam o amor - em âmbito trovadoresco -, ou como dirigem a própria vida - em âmbito mais lato, como parece ser o caso tratado nesta nossa composição. Esta dualidade sensatez/insensatez está também presente nos textos bíblicos, justamente em Eclesiastes, a começar no prólogo, no qual a sabedoria e a loucura são evocados na experiência e observação do Qohelet ("Apliquei o coração a conhecer a sabedoria e a conhecer os desvarios e as loucuras; mas vim a saber que também isso era desejo vão”, Eclesiastes 1:17), e muito particularmente na segunda metade do livro, ocupando a sabedoria um lugar preponderante na reflexão. A mesma oposição sábio/louco encontra-se igualmente no típico discurso de ética sapiencial, conforme desenvolvido em Provérbios:

Os sábios entesouram o conhecimento; porém a boca do insensato é uma destruição iminente (Provérbios 10:14).

Todo prudente procede com conhecimento, mas o tolo expõe a sua loucura (Provérbios 13:16).

\footnotetext{
17 Esta composição parece dialogar com uma outra de amigo (BASE DE DATOS, B1027/V617), na qual a figura feminina, para não perder o amor do seu amigo, concede dar-lhe o que ele pede (subentende-se que seja o ben) - "fazelo quer' e non farei end' $a^{\prime \prime}$-, desde que ele a proteja: "E, se vós fordes amigo leal,/ guardaredes vossa senhor de mal".

18 Os trovadores entre a primeira e a segunda geração usavam o termo com o mesmo sentido que os seus congéneres occitânicos, mas, a partir da segunda geração, há uma reconceptualização do tema. Sobre o conceito de mesura no contexto da lírica galego-portuguesa, ver Correia (2016, p. 96).
} 
Quem anda com os sábios será sábio; mas o companheiro dos tolos sofre aflição (Provérbios 13:20).

Este último aforismo retirado do livro de Provérbios, aliado ao pensamento do Qohelet concernente à postura perante a vida e à garantia da felicidade enquanto "dom de Deus", permite-nos uma compreensão mais apurada do papel desempenhado pela mulher no trabalho do trovador. Esta avaliação positiva da sua influência possibilita, por consequência, que o trabalho seja encarado como algo bom, por sua vez capaz de o fazer usufruir dos bens que dele advêm.

A última estrofe encerra todas as dúvidas sobre o alcance moral deste cantar. O sujeito poético afirma que a alegria que sente emana de Deus - "[...] son mui ledos quantos con $\mathrm{El}$ son" - opondo de forma veemente riqueza/tristeza e pobreza/alegria. Ora, em momento algum a pobreza chega a ser tema no texto. $\mathrm{Na}$ verdade, este tipo de construção de dupla oposição, com laivos claramente proverbiais, relembra uma vez mais o Qohelet em alguns dos seus aforismos: "Melhor é uma mão cheia, com descanso, do que ambas as mãos cheias, com trabalho e aflição de espírito" (Eclesiastes 4:6), ou ainda "Melhor é o mancebo pobre e sábio do que o rei velho e insensato, que não se deixa mais admoestar" (Eclesiastes 4:13). Com efeito, esta sentença construída por meio de uma comparação, realçada através de opostos, visa um nítido didatismo. Trata-se de uma típica construção do mashal $^{19}$, uma forma literária sapiencial muito utilizada no livro de Provérbios. É, de facto, muito significativo que o nosso trovador termine o seu cantar d'amor recorrendo às mesmas fórmulas sapienciais, fazendo a seguinte declaração: "[...] ca un pobre ledo mil tanto val/ ca rico triste en que non á prazer" Estes dois últimos versos condensam todo o sentido do texto e plasmam de forma muito evidente a doutrina contida no Qohelet.

Ora, a utilização deste livro bíblico como fonte por João Airas parece manter-se na composição “Todalas cousas eu vejo partir” (BASE DE DATOS, B963/ V550), que sucede o nosso texto nos manuscritos. Vejamo-lo.

Todalas cousas eu vejo partir

do mund' en como soian seer,

e vej' as gentes partir de fazer

ben que soia, ;tal tempo vos ven!,

mais non se pod' o coraçon partir

do meu amigo de mi querer ben.

Pero que ome part' o coraçon

das cousas que ama, per bõa fe,

e parte-s' ome da terra ond' é,

e parte-s' ome d' u grande prol ten,

non se pode partilo coraçon

do meu amigo de mi querer ben.

19 Cf. Alves (1991, p. 39), McKane (1970, p. 22-26) e Djaballah (1994, p. 26).

20 Note-se que a existência de composições que se desenvolvem em torno de uma sentença, como a que encerra o poema de João Airas - "ca un pobre ledo mil tanto val/ ca rico triste en que non á prazer" - é tradicionalmente atribuída aos rasgos popularizantes que alguns estudiosos acreditam existir na lírica galego-portuguesa. A propósito especificamente de João Airas, diz o seu editor "[...] su gusto por lo popular se refleja en la predilección por la fraseología y sobre todo por el proverbio que conforma el fondo de muchas composiciones", isto é, "[...] seu gosto pelo popular se reflete em sua predileção pela fraseologia e principalmente pelo provérbio que forma o pano de fundo de muitas composições" (RODRIGUEZ, 1980, p. 53). 
Todalas cousas eu vejo mudar, mudan-s' os tempos e muda-s' o al, muda-s' a gente en fazer ben ou mal, mudan-s' os ventos e tod' outra ren, mais non se pod' o coraçon mudar

do meu amigo de mi querer ben (BASE DE DATOS, B963/V550).

Neste texto, partindo do clássico tópico do mundo às avessas, o trovador lamenta a inversão dos valores num mundo marcado pela mudança através de uma perspetiva feminina, como forma de acentuar o valor do amor do amigo. A protagonista contrapõe, assim, a inconstância do mundo à firmeza inquebrantável do amor do namorado.

Ora, a forma como o tema é exposto - primeiro, assinala-se tudo o que invariavelmente sofre mudança, para depois acentuar o que nunca muda - é muito semelhante aos primeiros versículos do Qohelet:

Uma geração vai, e outra geração vem; mas a terra para sempre permanece. E nasce o sol e põe-se o sol, e volta ao seu lugar de onde nasceu. O vento vai para sul, e faz o seu giro para o norte; continuamente vai girando o vento, e volta, fazendo os seus circuitos. Todos os ribeiros vão para o mar e, contudo, o mar não se enche; para o lugar para onde os ribeiros vão, para aí tornam eles a ir. Todas estas coisas se cansam tanto, que ninguém o pode declarar: os olhos não se fartam de ver, nem os ouvidos de ouvir (Eclesiastes 1:4-8).

Para além da notável semelhança a nivel de construção de ideias - o que é imutável na composição de João Airas é o amor do amigo, e no livro bíblico, a Terra -, o trovador galego aproveita ainda a ideia da mudança dos tempos ("[...] uma geração vai e uma geração vem" no Qohelet) e dos ventos para realçar a solidez desse amor.

Neste ponto, torna-se pertinente fazer uma breve reflexão sobre a colocação dos textos abordados nos manuscritos. Os cantares de João Airas surgem nos testemunhos B e $\mathrm{V}^{21}$ divididos em secções de escárnio e maldizer e amigo e, dentro da última, em dois blocos: um que reunia as composições de amigo, outro que reunia as de amor. Para Resende de Oliveira, isto é indicativo de que estes estariam muito provavelmente inseridos num cancioneiro individual adicionado às duas grandes compilações (OLIVEIRA, 1994, p. 197). As duas composições que citámos surgem nos dois manuscritos no final do bloco correspondente aos cantares do amor, sendo que a última, a de amigo, aparece deslocada do respetivo bloco. O que as duas composições têm em comum é o tom. Embora pertencendo a géneros diferentes - a primeira ao de amor, com sujeito da enunciação masculino, a segunda ao de amigo, com sujeito da enunciação feminino -, os dois cantares do burguês de Santiago partilham o carácter reflexivo sobre diferentes aspetos do comportamento humano, estabelecendo o amor, e em última instância o cantar, como elemento redentor e regenerador, através do qual se poderá alcançar a felicidade. Parece-nos, pois, que a temática moral que os dois textos carregam, que, no nosso entender, devem muito às ideias transmitidas pelo Qohelet, e o seu carácter híbrido e de dificil categorização podem muito bem justificar este posicionamento.

21 Cancioneiro da Biblioteca Nacional e Cancioneiro da Vaticana, respetivamente. 
Esta viagem que fizemos pelos textos de João Airas deixou-nos com a sensação de não poder olhar para uma composição de forma isolada, nomeadamente no que à retórica de amor diz respeito. Há um certo universo argumentativo, contracorrente, que parece aflorar da sua poética. Há-o no que diz respeito à crítica aberta que é realizada aos trovadores que faziam uso de uma linguagem mais disfórica e pessimista; e há-o também no que concerne à proposta de uma nova formulação da temática da solicitação do bem (ou recompensa amorosa). Só lendo-os em conjunto conseguimos verificar a sua concretização. E como navega o burguês de Santiago nos vários mares literários que tinha à sua disposição?

Sabemos que o trovador galego revela um conhecimento muito profundo da poesia occitânica, nomeadamente na utilização de outros géneros mais comuns a esta tradição, como é o caso da pastorela ${ }^{22}$, e na adoção desse tom mais otimista do que aquele que encontramos no género de amor galego-português, mas sabemos também que não o faz de forma exata. Na verdade, muitos dos seus textos assemelham-se a exercícios literários que procuravam renovar a já repetitiva retórica galego-portuguesa de amor, conciliando-a com outras tradições literárias fecundas em matéria poética. Assim conseguimos perceber que esta teorização sobre o amor patente em vários dos seus textos, e sobre a figura última da mulher, capaz de o fazer proceder de forma justa e sensata, o autorize a recorrer à matéria bíblica, que provavelmente deveria conhecer da versão vulgata que circulava na época, para tecer considerações de alcance moral, e, em última instância, justificar a adaptação dessa mesma matéria em prol da mensagem que o mesmo quereria passar em ambiente trovadoresco. Com isto, vemos criada uma poética muito própria e original, de carácter excecional no seio dos cancioneiros galego-portugueses.

\section{The poetry of João Airas de Santiago and the Bible's wisdom literature}

Abstract: The poetic universe of João Airas de Santiago does not end with the 81 compositions that have reached us. Following a singing of love that presents moral sirvent's characteristics, we will see how Santiago's bourgeois reflects on several aspects of human behaviour, inspired by his readings of the book of Ecclesiastes. The analysis of this remarkable intertextuality intends to show how the presence of biblical thought in the troubadour's texts seems to provide the legitimisation of the troubadour's activity, made possible by love.

Keywords: Bible. Ecclesiastes. João Airas. Medieval Galician-Portuguese lyric. Medieval literature.

\section{REFERÊNCIAS}

A BÍBLIA Sagrada: Antigo e Novo Testamento. Tradução J. F. Almeida. 3. ed. Rio de Janeiro: Imprensa Bíblica Brasileira, 1991.

AFONSO X. General estoria. Ed. A. Solalinde. Madrid: Junta para Ampliación de Estudios e Investigaciones Cientificas: Centro de Estudios Históricos, 1930. 
ALVES, H. Raízes da sabedoria bíblica. In: Livros sapienciais: XIII Semana Bíblica Nacional, III Semana Bíblica Diocesana do Funchal. Lisboa: Difusora Bíblica, 1991. p. 17-68.

BASE DE DATOS da Lírica Profana Galego-Portuguesa. MedDB): versión 3.10 [on-line]. Santiago de Compostela: Centro Ramón Piñeiro para a Investigación en Humanidades. [s. d.]. Disponivel em: http://www.cirp.gal/meddb. Acesso em: 25 ago. 2021.

BELL, A. The Hill Songs of Pero Meogo. Modern Language Review, n. 17, p. 258-262, 1922.

CORREIA, C. S. S. C. A difusão ibérica da linguagem dos trovadores galego-portugueses. 2016. Tese (Doutorado em Estudos Literários, Culturais e Interartístico) - Faculdade de Letras, Universidade do Porto, Porto, 2016. Disponivel em: https:/ / repositorio-aberto.up.pt/bitstream/10216/116259/2/293823.pdf. Acesso em: 25 nov. 2021.

DEYERMOND, A. Old Testament elements in two Cantigas de Amigo. In: MACEDO, H. (ed.). Studies in Portuguese Literature and History in Honor of Luis de Sousa Rebelo. Londres: Tamesis, 1992. p. 21-28.

DJABALLAH, A. Les paraboles aujourd'hui. Québec: Collection Sentier, 1994.

DOUKHAN, J. B. Ecclesiastes: all is vanity. Idaho: Pacific Press, 2006.

FERREIRA, M. R. Águas doces, águas salgadas: da funcionalidade dos motivos aquáticos na Cantiga de Amigo. Porto: Granito Editores e Livreiros, 1999.

FERREIRA, M. R.; MIRANDA, J. C. R. Meendinho ou as ondas em águas paradas. In: O cancioneiro da ajuda cen anos despois. Santiago de Compostela: Xunta de Galicia, 2003. p. 293-312.

MAUSSION, M. Le mal, le bien et le jugement de Dieu dans le livre de Qohélet. Fribourg: Editions Universitaires, 2003.

MCKANE, W. The meaning of masal. In: Proverbs: a new approach. London: SCM Press; Philadelphia: Westminster Press, 1970. p. 22-33.

MCKENNA, J. E. The concept of Hebel in the Book of Ecclesiastes. Scottish Journal of Theology, v. 45, n. 1, p. 19-28, Feb. 1992.

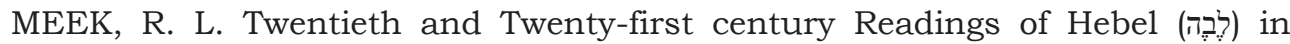
Ecclesiastes. Currents in Biblical Research, Kansas City, v. 14, n. 3, p. 279-297, Jun. 2016.

MIRANDA, J. C. R. Aurs Mesclatz ab argen: sobre a primeira geração de trovadores galego-portugueses. Porto: Edições Guarecer, 2004.

MIRANDA, J. C. R.; OLIVEIRA, A. R. A segunda geração de trovadores galego-portugueses: temas, formas e realidades. In: Medioevo y literatura. Actas del V congreso da la Asociación Hispánica de Literatura Medieval. Granada: Universidad de Granada, 1995. p. 499-512. Entretanto incluído em OLIVEIRA, A. R. O trovador galego-português e o seu mundo. Lisboa: Editorial Notícias, 2001. p. 97-110.

OLIVEIRA, A. R. Depois do espectáculo trovadoresco: a estrutura dos cancioneiros medievais e as recolhas dos séculos XIII e XIV. Lisboa: Colibri, 1994.

RAYMOND, P. (ed.). Dictionnaire d'hébreu et d'araméen bibliques. Paris: Cerf, 1991. 
DOSSIE

RIBEIRO, C. A. O lirismo e a emergência da subjectividade (a propósito da pastorela de Joan Airas de Santiago). In: TORO PASCUA, M. I. (ed.). Actas de III Congreso de la Associación Hispánica de Literatura Medieval (Salamanca, 3 al 6 de octubre de 1989). Salamanca: Biblioteca Española del siglo XV, 1994. t. I, p. 79-83.

VASCONCELlOS, C. M. H. Cancioneiro da ajuda. Lisboa: Imprensa Nacional-Casa da Moeda, 1990. 2v.

WEEKS, S. Eclesiastes 1-5: a critical and exegetical commentary. London/New York: T\&T Clark, 2020. v. 1. 